\title{
A HISTÓRIA DOS KAINGANG DA TERRA INDÍGENA LINHA GLÓRIA, ESTRELA, RIO GRANDE DO SUL/BRASIL: SENTIDOS DE SUA (RE)TERRITORIALIDADE
}

\section{The history of Kaigang people from Linha Glória indigenous land, Estrela, Rio Grande do Sul/Brazil: Senses of their (re)territoriality}

Juciane Beatriz Sehn da Silva

Historiadora

sehn@universo.univates.br

Luís Fernando da Silva Laroque

Doutor em História, Prof. na Univates, Lajeado, RS

1flaroque@terra.com.br

Artigo recebido em 28/04/2012 e aceito para publicação em 11/07/2012

RESUMO: O presente trabalho versa sobre a história do grupo indígena Kaingang da Terra Indígena Linha Glória, localizada no município de Estrela, Vale do Taquari, Rio Grande do Sul, no que se refere às suas movimentações pelo tradicional território Kaingang. Por meio deste estudo, temos a intenção de mostrar que este grupo, apesar de ter permanecido fora das terras indígenas tomadas como oficiais pelo Estado Nacional, onde residem muitos de seus parentes, continuou a vivenciar práticas culturais da tradição Kaingang. O objetivo do estudo é também demonstrar que esses indígenas têm sido agentes de sua própria historicidade, e os sentidos pelos quais envolvem sua territorialidade têm a ver com a cosmologia tradicional Kaingang, que se constitui numa verdadeira riqueza cultural e patrimonial para o Vale do Taquari.

Palavras-Chave: Kaingang. História. Terra Indígena Linha Glória. Territorialidade.

ABSTRACT: This paper discusses the history of the Kaingang indigenous group that is located in Linha Glória Indigenous Land, in Estrela, Taquari Valley, state of Rio Grande do Sul, Brazil, and is focused on their movements in the Kaingang traditional territory. Through this research, we intend to show that this group, despite of having been placed in the outside of the indigenous lands taken by the Brazilian National State, where reside many of their relatives, continued to experience cultural practices of Kaingang tradition. The main objetive of this study is also to demonstrate that these indigenous people have been protagonists of their own historicity and the senses with which they involve their territoriality have strong relations to the Kaingang traditional cosmology, and this is a true cultural and heritage richness for Taquari Valley.

Key-words: Kaingang. History. Linha Glória Indigenous Land. Territoriality. 


\section{INTRODUÇÃO}

A região do Vale do Taquari, localizada na macrorregião nordeste do Rio Grande do Sul/Brasil foi, como um todo no passado, um tradicional território de ocupação indígena. Estudos arqueológicos no Vale do Taquari, iniciados em 2000, com a criação do Setor de Arqueologia da Univates, sob a coordenação da professora arqueóloga Neli Teresinha Galarce Machado, comprovam essa afirmação. A partir do trabalho do Setor de Arqueologia/Univates, vários artefatos de cultura material foram encontrados e muitos sítios arqueológicos identificados, atestando, assim, a ocupação de grupos pré-coloniais ou pré-históricos na região em questão (FIEGENBAUN, 2006). Diversos estudos de caráter arqueológico já avançaram no sentido de demonstrar a ocupação indígena, com base na cultura material encontrada em sítios arqueológicos. A título de exemplo, apontamos as dissertações de mestrado: "O contexto ambiental e as primeiras ocupações humanas no Vale do Taquari-RS" (2008), em que Marcos Rogério Kreutz procura compreender a relação pretérita homem e ambiente por meio da análise e caracterização do contexto ambiental em sítios arqueológicos do Vale do Taquari. Nesse sentido, há também o estudo de Jones Fiegenbaum, intitulado "Um Assentamento Tupiguarani no Vale do Taquari/RS" (2009).

Embora grande parte do material cerâmico encontrado esteja identificado como sendo de grupos horticultores Guarani, sabe-se também que o espaço geográfico compreendido entre os rios Jacuí e Taquari (ou rio das Antas), ou Serra do Botucaraí, é reconhecido como território do grupo Kaingang, fazendo parte do processo de ocupação indígena, não só Guarani, mas também Kaingang (CHAGAS, 2005).

Nesse sentido, há uma relação de pertencimento do grupo Kaingang da Linha Glória/Estrela com o atual espaço denominado região do Vale do Taquari, isto é, eles estariam retornando ao seu antigo território. E uma forma de marcar o território tradicional, segundo a tradição Kaingang, se dá mediante o enterramento do umbigo do recém-nascido, prática que, de acordo com relatos de Maria Antônia Soares, filha de Manoel Soares, patriarca da Terra Indígena Linha Glória, marca o retorno do grupo ao atual espaço, ou seja, é "onde o umbigo de Manoel estava enterrado" (GONÇALVES, 2008, p. 65).

Tradicionalmente, os indígenas Kaingang ocupavam uma imensa área do Brasil Meridional, e esta compreendia desde a região Sudeste até o extremo sul do Brasil, formando assim "O Grande Território Kaingang”. Os limites dessa ocupação abrangiam desde o rio Tietê, no sudeste, passando pelos Estados de Paraná, Santa Catarina, e, no Rio Grande do Sul, o território se estendia até os rios Jacuí e Ibicuí. Para oeste, a ocupação Kaingang avançava para a província argentina de Misiones.

Atualmente, os Kaingang ocupam cerca de trinta reduzidas áreas, distribuídas sobre seu antigo território, nos Estados de São Paulo, Paraná, Santa Catarina e Rio Grande do Sul. Segundo Rogério Rosa (2009), são cerca de trinta mil indivíduos, concentrados, na sua grande maioria, em terras indígenas situadas entre as bacias dos rios Tietê (norte), Paranapanema, Iguaçu, Uruguai, Jacuí e tributários do sistema Guaíba-Patos (Sul), Paraná (Oeste) e Oceano Atlântico (Leste).

No Rio Grande do Sul, existem atualmente nove Terras Indígenas reconhecidas pelo Estado Nacional, sendo que, em cinco delas, residem somente indígenas Kaingang e, nas outras quatro, há indígenas Guarani e Kaingang. São elas: Cacique Doble (localizada na cidade com o mesmo nome), Carreteiro (localizada em Água Santa), Ligeiro (localizada na cidade de Charrua), Votouro (em São Valentin), Nonoai (situada em Nonoai, Rodeio Bonito e Planalto), Guarita (em Redentora, Tenente Portela e Miraguai), Inhacorá (em Santo Augusto), Rio da Várzea (nos municípios de Liberato Salzano e Nonoai), Iraí (em Iraí) (MARCON, 1994). Além dessas reservas, reconhecidas como tal, existem outros agrupamentos indígenas, que ocupam diferentes espaços no estado. No Vale do Taquari, além da Terra Indígena Linha Glória, Estrela, podemos citar a Terra Indígena Fochá, localizada na cidade de Lajeado, ambas formadas por indígenas da etnia Kaingang.

Este estudo foi realizado com base em fontes bibliográficas, material historiográfico (ensaios, artigos e dissertações de mestrado e doutorado) e em fontes documentais, tais como jornais (Jornal "Nova Geração" e Jornal "A Folha de Estrela", do municí- 
pio de Estrela) e documentos do Ministério Público Federal/Lajeado. Além disso, embasados em Brand (2000) e Mussi (2000), nos utilizamos também da metodologia de História Oral durante a pesquisa de campo, tanto na Terra Indígena em Estrela, como no contato com atores vinculados a agências oficiais ou ligados à pesquisa. Como base teórica para a análise dos dados estudados, nos respaldamos nos trabalhos de Barth ([1969] 2000), Brandão (1986), Martins (1997) e Tommasino (2000, 2001 e 2005).

\section{RELAÇÃO COSMOLÓGICA DO GRUPO COM O TERRITÓRIO OCUPADO}

O retorno dos Kaingang à Terra Indígena Linha Glória, área localizada no tradicional território do grupo, tem a ver com o que Tommasino (2001, p. 13) conceitua como "reterritorializar-se", ou seja, "estão (re) ocupando espaços que foram áreas de caça e coleta no passado e, agora, mesmo transformados pelo branco, voltam a ser locais de atividades de subsistência física e cultural". Nesse sentido, constatamos que, ao se instalarem nesse local, os indígenas de Linha Glória estão se reapropriando desse espaço físico e recriando nele um novo território de acordo com seus próprios códigos culturais.

Ao longo dos tempos, os grupos indígenas foram sistematicamente sendo expropriados de suas condições de subsistência e, entre estas, encontra-se a terra. No contato dos indígenas Kaingang com a sociedade nacional, em meados do século XIX, tentou-se produzir uma definição de território (e de terra) única para todos os grupos indígenas, definição esta que se inscreve nas concepções econômico-jurídicas ocidentais de terra e território e que nada tem a ver com as concepções que os indígenas têm sobre terra e território.

Os Kaingang denominam $G a$ o território tribal. $G a$ também é terra, solo. $G a$ refere-se, portanto, a coisas bem concretas, fundamentais para a existência de qualquer sociedade. Assim, $G a$ é o lugar onde os Kaingang se realizam como sociedade específica fundada num espaço físico, social e simbolicamente transformado. Território é onde os Kaingang vivem de acordo com suas metades e seções, segundo regras de reciprocidade e aliança. É a base material sobre a qual imprimem seus padrões identitários, de consanguinidade e afinidade, de residência uxorilocal e descendência patrilinear (TOMMASINO, 2005). Nesse sentido, ressaltamos que a uxorilocalidade é o padrão de residência adotado pelos indígenas Kaingang após o casamento. No passado, os Kaingang possuíam grandes casas comunais habitadas por homens, suas mulheres, seus filhos não casados, suas filhas casadas e seus genros com os respectivos filhos e filhas. Atualmente, os Kaingang não possuem mais grandes casas comunais, mas é comum que as filhas, ao se casarem, tragam os maridos para a casa dos pais. Quando o casal novo passa a uma casa própria, em geral fica localizada ao lado da casa dos pais (VEIGA, 2006).

No decorrer do século XX e nas primeiras décadas do século XXI, os processos expropriatórios reduziram consideravelmente os territórios indígenas e mesmo as terras indígenas anteriormente delimitadas e/ou demarcadas foram atingidas. Segundo Lígia Simonian (2009), o estado, por meio de seus gestores, é que tem sido o responsável pela expropriação desses espaços enquanto posse indígena.

No Rio Grande do Sul, os toldos indígenas (denominação dada às terras indígenas demarcadas ou não), no decorrer do século XX, todos eles foram expropriados parcialmente, sendo alguns extintos, quer diretamente pelo governo estadual, quer por fazendeiros, empresários rurais e agricultores sem-terra. De acordo com Simonian, temos:

Todo este processo teve início com invasões diretas, o que inclui outras violências diversas praticadas contra os indigenas, inclusive assassinato de lideranças. Por sua vez, a maioria destes invasores buscou a intervenção das autoridades, incluindo as jurídicas, para se respaldar. E em muitos casos tais invasões lograram êxito em suas demandas (SIMONIAN, 2009, p. 495).

As políticas e ações anti-indígenas nos estados do Sul do Brasil reduziram drasticamente áreas delimitadas e/ou demarcadas no período anterior ao século XX e no atual. Como exemplo desse processo expropriatório, Lígia Simonian (2009) aborda o caso do aldeamento de Nonoai, criado em 1848, e que, logo 
passou a ser alvo dos exploradores de erva-mate e criadores de gado que invadiram suas terras. Inclusive o mapa do aldeamento, produzido no século XIX, com uma vista ampla do território, que foi roubado por não índios interessados nas terras e na madeira da floresta imensa de araucária. Outra estratégia usada pelos não índios interessados nas terras e demais recursos naturais dos Kaingang do Rio Grande do Sul foi o assassinato por emboscadas.

No Rio Grande do Sul, a redução ainda maior das áreas indígenas se deu em 1962, no governo de Leonel Brizola, período em que os indígenas Kaingang perderam extensões e significativas áreas de terra e sofreram violências, inclusive como a fome e a tortura. Nos decretos e leis, o argumento legitimador da expropriação foi o de que os Kaingang tinham muita terra para pouco resultado produtivo, e o Estado necessitava de terras para os agricultores sem-terras a fim de fazer uma reforma agrária. $O$ cálculo para a redução das terras indígenas no Sul foi baseado no módulo mínimo utilizado pelo Instituto Nacional de Colonização e Reforma Agrária (INCRA), sem considerar que a população indígena, como qualquer outra, é suscetível de crescimento vegetativo (TOMMASINO, 2001). Nesse sentido, a população de diversas áreas indígenas aumentou significativamente, o que resultou em problemas como a falta de terras, o que, somado à deteriorização da qualidade do solo pelo desgaste e degradação do meio, impede que os indígenas tenham plenas condições de sobrevivência.

Visto que as reservas não lhes dão garantias de viver segundo seus códigos culturais, os Kaingang acabam saindo de terras oriundas do Planalto Rio-Grandense, dando continuidade às tradicionais formas de encaminhar seus ciclos socioeconômicos. Há aproximadamente quatro décadas, existe uma intensificação da saída destes grupos das terras do Planalto. É comum que essas famílias Kaingang procurem se organizar novamente nas proximidades de cidades de médio e grande porte, como no caso de Porto Alegre, bem como em alguns municípios da serra gaúcha e no Vale do Taquari, para que nesses espaços ocupados possam dar continuidade à sua cultura (OLIVEIRA, 2010).

Os indígenas Kaingang sempre resistiram à expropriação de suas terras, porém, diante do uso da força, não puderam fazer muito por anos e, mesmo, décadas. Em fins da década de 1970, as lutas dos Kaingang pela a retomada de suas terras expropriadas passaram a ser mais intensas. Com a Constituição de 1988, os indígenas se fortaleceram; tendo o respaldo da lei, persistiram com suas demandas e lutas, tendo sido vitoriosos em muitas delas (SIMONIAN, 2009). Atualmente, tratando-se do Rio Grande do Sul Kaingang, Guarani e Charrua, têm se fundamentado no texto constitucional vigente e lutado pelo respeito a seus direitos territoriais.

Nesse contexto é que se insere a trajetória histórica do patriarca Kaingang Manoel Soares da Terra Indígena Linha Glória, no município de Estrela. Há fortes indicativos de que a família de seu Manoel Soares, a de suas duas esposas, bem como a de algumas dos seus parentes, permaneceram fora dos aldeamentos criados pelo governo, acarretando, consequentemente, o estabelecimento do grupo na cidade de Santa Cruz do Sul, durante as décadas de 1950 e 1960. Nessa época, os indígenas Kaingang viviam sob a repressão do então governador Leonel Brizola, conhecida como a "caçamba do Brizola", que carregava os indígenas para os aldeamentos à força. Além disso, na década de 1960, as Terras Indígenas (TIs) Kaingang viviam sob o regime do "Panelão, instituído pelo Serviço de Proteção ao Índio (SPI). Nesse regime, os indígenas eram obrigados a deixar de trabalhar em suas roças para fazer isto na roça do Posto, e a comida era feita em uma cantina e servida coletivamente em grandes panelas (VEIGA, 2011, texto digital). Durante as décadas de 1950 e 1960 é que surgiram os primeiros acampamentos indígenas nas cidades e beiras de rodovias. Eles se configuravam praticamente como único espaço fora do sistema anteriormente mencionado, o qual caracterizava o período.

Fora do aldeamento e não tendo um território garantido para ocupar, o grupo liderado por Manoel Soares precisou migrar de Santa Cruz do Sul (cidade próxima ao Vale do Taquari), de onde teriam sido expulsos. Em vista disso, passaram a ocupar o trevo de acesso a Bom Retiro do Sul (município do Vale do Taquari) e, posteriormente, estabeleceram-se, por orientação do DAER, no local onde estão atualmente, isto é, no Km 360 da rodovia BR 386, em Estrela. 
Há toda uma relação cosmológica do grupo com o atual território, porém esse espaço, apesar de já estar ocupado há cerca de quarenta anos por eles, não é reconhecido como Terra Indígena. Parte das terras compreendidas pela aldeia às margens da BR 386 é de domínio do DAER e outra parte é de propriedade particular do senhor Erivelto Villlanova. Em 2006, o então governador do Rio Grande do Sul, Germano Rigotto, com respaldo da legislação, autorizou a construção de casas para os indígenas Kaingang na propriedade de Villanova (ÍNDIOS, Jornal A HORA, 26/01/2011). De lá para cá, a questão da terra se acentuou para este grupo Kaingang, que luta para ter seu espaço ampliado e reconhecido como Terra Indígena junto à FUNAI.

É importante compreendermos que, historicamente, os Kaingang foram sendo expropriados de seus tradicionais territórios por conta de políticas que visavam à ocupação das terras ditas "devolutas", incentivadas pelo governo por meio da colonização e da imigração. Diante de toda esta questão, os indígenas Kaingang, que atualmente constituem a Terra Indígna Linha Glória, foram se locomovendo no espaço e resistindo às pressões da sociedade nacional, sobretudo à estratégia política dos aldeamentos então criados pelo governo no século XIX. Dessa forma, vieram a ocupar o município de Santa Cruz do Sul e, na década de 1960, deslocaram-se para o Vale do Taquari. Constatamos, a partir da análise dos dados pesquisados, que a vinda para esta região foi motivada por sua tradição cosmológica, ou seja, retornaram para espaços ocupados em tempos pretéritos por seus antepassados. Nesse sentido, o fato de estarem se (re) territorializando se deve, sobretudo, a uma relação de pertencimento com o atual território, ou seja, estão retornando a espaços que já foram seus no passado.

Contudo, há "marcas" no território que fundam a existência deste grupo neste ambiente e essas "marcas" são reconhecidas por eles por meio de elementos simbólicos como, por exemplo, resquícios de fogueiras que foram deixadas pelos seus antepassados, além da prática do enterramento do umbigo, pois, segundo relatos de uma das lideranças da Terra Indígena em questão, vieram em busca do local onde o umbigo do patriarca Manoel Soares foi enterrado. Assim, podemos compreender melhor a relação cosmológica e os sentidos pelos quais este grupo buscou fixar-se no Vale do Taquari.

\section{HISTORICIDADES E LUTAS DA TERRA INDÍ- GENA LINHA GLÓRIA: KAINGANG COMO SUJEITOS DE SUA HISTÓRIA}

Nas décadas de 1950 e 1960, quando os Kaigang estavam estabelecidos na cidade de Santa Cruz do Sul, seu Manoel veio a se "casar" com Dona Lídia, que era natural de Herveiras (antigo distrito de Sinimbu), e depois com Dona Eva. Sobre o local onde morava, em Santa Cruz do Sul, uma das matriarcas informa que era conhecido por eles como "Vila Macaca"; hoje sabem que é chamado de "Bairro Santo Antônio" (EC, 17/03/2011, p. 1). O fato de esse grupo Kaingang permanecer fora dos aldeamentos se deve à política repressiva de Leonel Brizola que, entre 1959 e 1962, conduzia os indígenas à força por meio das chamadas "caçambas do Brizola", para servirem de mão de obra aos fazendeiros.

Portanto, a proveniência do grupo antes de se estabelecer no Vale do Taquari, conforme já referido anteriormente, é do município de Santa Cruz do Sul, onde se encontra o atual Parque da Gruta (antiga Gruta dos Índios). Justamente pela criação do parque é que tiveram que sair da região, onde trabalhavam na venda de artesanato e prestavam serviços aos fumicultores. Diante desse fato, tiveram que ir à busca de trabalho na cidade de Montenegro e em outros locais. Trabalharam no corte de mato nos municípios de São Sebastião do Caí e Montenegro (BIRCK, 2002). Também moraram debaixo de pontes na cidade de Venâncio Aires.

Quando ainda moravam em Santa Cruz do Sul, o pai de Manoel veio a falecer. Apenas a mãe ainda permanecia no grupo. Ao saírem de Santa Cruz, seu Manoel, Dona Lídia e Dona Eva, com seus respectivos filhos, foram em busca de sustento e talvez "procurando o lugar onde o umbigo [de Manoel] foi enterrado", que é reconhecida por seus descendentes como a região onde vivem atualmente (GONÇALVES, 2008, p. 64). Na década de 1960 , teriam chegado ao município de Bom Retiro do Sul, ocupando o trevo de acesso a esse município, um pouco abaixo (ao sul) do local onde vivem atualmente, pertencente à jurisdição do município de Estrela. Passado algum tempo, acabaram fixando-se no atual local, por indicação da Polícia Federal (BIRCK, 2002, p. 2). 
A história dos Kaingang da Terra Indígena Linha Glória, Estrela, Rio Grande do Sul/Brasil: Sentidos de sua (re)territorialidade Juciane Beatriz Sehn da Silva, Luís Fernando da Silva Laroque

Com base na análise pericial realizada pela antropóloga Miriam Chagas (2005), o grupo Kaingang da Terra Indígena de Estrela se constitui a partir de um único grupo familiar, que teve origem na descendência de Manoel Soares com duas mulheres: Lídia Soares e Eva Rosalina de Mello. Ambas também são referidas como sendo aparentadas por parte do avô de Lídia, referido como Antônio Ramão Soares. Atualmente, Eva é companheira do filho mais velho, de Manoel com Lídia, isto é, José Alvício Soares, conhecido como Xicão. Sobre os filhos de Manoel com as referidas esposas, Chagas informa o seguinte:

Entre as pessoas que hoje estão na área, oito são filhos de Manoel com Eva e onze são filhos de Manoel com Lidia. Também há um ramo familiar de um irmão de Manoel que se chama Bento. Atualmente um filho de Bento, de nome Paulo, é morador do local. Consta que também Bento chegou a morar ali. As outras moradias são compostas pelos filhos de Manoel com essas duas mulheres citadas. Foi informado também que outra mulher de Manoel chegou a morar na área. Ela foi referida como dona Sirce e que atualmente moraria em Venâncio Aires. Ela também teria tido filhos com Manoel e saído da área um pouco antes de Manoel morrer atropelado, a cerca de 15 anos atrás (1990) (CHAGAS, 2005, p. 10).

Seguindo a análise das relações de parentesco, Chagas (2005, p. 11) observa ainda que, basicamente, nesta aldeia, há três gerações de descendentes de um mesmo tronco velho de Manoel Soares (tronco velho é uma denominação utilizada na tradição Kaingang), com suas duas primeiras mulheres, mantendo uma descendência entre pessoas do próprio grupo. Dona Lídia, que se diz parente de Dona Eva, refere que seu avô Antônio Ramão tinha o sobrenome Soares, podendo ser, de algum modo, parente de Manoel.

Da descendência de Manoel com Lídia, nasceram os indígenas de nomes Maria Antônia Soares (52 anos), José Alvício Soares (51 anos), Altair Soares (45 anos), Pedro Antônio Soares (42 anos), Jair Soares (39 anos), Clarice Soares (38 anos), Carlos Soares (37 anos), Márcia Soares (35 anos), Maria Sandra Soares
(32 anos), Andréia Soares (31 anos), Maria Conceição Soares (25 anos) e Adelar Soares, sendo que, deste último, não obtivemos informação de idade. O grupo familiar formado pela ligação de Manoel com Eva, por sua vez, é constituído por nove filhos, conforme informa o depoente, sendo eles: Janete Soares (37 anos), Marcos de Mello (36 anos), Márcio de Mello (35 anos), Carlos André de Mello (31 anos), Paulo Alexandre de Mello (28 anos), Vanderlei de Mello (26 anos), Leandro de Mello (23 anos), Claudete e André de Mello (EE, 22/03/2011, p. 1). Destes dois últimos filhos de Dona Eva não obtivemos informações de idade.

Conforme indica Chagas (2005), Manoel Soares teria tido ainda uma terceira esposa, de nome Sirce (natural de Venâncio Aires), com quem também teve filhos, porém, devido ao fato de ela ter saído da aldeia um pouco antes de Manoel falecer, em 1990, e retornado para Venâncio Aires, não temos conhecimento de ligação destes com o grupo atualmente. $\mathrm{O}$ que se sabe é que Sirce seria uma mulher "de fora" do grupo. A denominação "ser de fora", conforme a antropóloga Miriam Chagas (2005), não implica estar impedido de participar das relações de parentesco, ou seja, uma pessoa que se casa dentro da aldeia será, em alguma medida, "englobada" no grupo, passando a compor o círculo de parentesco.

Esta realidade vivenciada pelos indígenas da Terra Indígena Linha Glória, que por diferentes razões acabam relacionando-se com não indígenas, vindo a se casar com eles, é um processo que já vem de muitos anos, fazendo parte da realidade não só deste grupo, mas também de outros grupos indígenas. Segundo a análise de Miriam Chagas (2005), o grupo que basicamente contava com uma reprodução nos termos de uma mesma parentela familiar também encontrou, no casamento com os "de fora", uma forma de continuar se mantendo. Assim, os "de fora" são integrados ao grupo de parentesco e passam a ser considerados como de "dentro". Para compreendermos melhor essa questão cultural, buscamos nos respaldar nos estudos de Barth (2000), que retrata com grande clareza como se dá a definição de identidade dentro de um grupo. $\mathrm{Na}$ visão deste autor, a identidade de outra pessoa como membro de um mesmo grupo étnico implica num compartilhamento de critérios de avaliação e de julga- 
mento. Ou seja, é imprescindível que ambos estejam "jogando do mesmo jogo" para que façam parte do mesmo grupo, e isto implica na existência de critérios e sinais de identificação, que não necessariamente devem ser de caráter fenótipo, mas, sim, culturais.

Ao se estabelecer na região onde vivem atualmente, Manoel Soares e seu grupo tiveram como fonte de subsistência a venda de artesanato e a feitura de pequenas roças. Segundo relatos de uma das matriarcas da aldeia, seu Manoel tinha a preocupação de ensinar aos seus filhos a prática do artesanato, pois era uma forma de manter viva a cultura e também era uma fonte de subsistência do grupo (EC, 17/03/2011, p. 5). Nesse sentido, percebemos também, durante a fala do depoente $\mathrm{C}$, a forte atuação de Manoel Soares para a manutenção do grupo, o que pode ser verificado como uma característica determinante apontada por Laroque (2005) para a atuação das lideranças do século XX.

O patriarca da Terra Indígena, Manoel Soares, permaneceu como liderança do grupo Kaingang da Terra Indígena Linha Glória até 1990, quando veio a falecer, vítima de um acidente de trânsito. Dessa forma, assume a liderança da aldeia sua filha mais velha, Maria Antônia Soares, que irá permanecer à frente do grupo até 2009, quando então assumiu seu lugar sua irmã, Maria Sandra Soares, que permaneceu até meados de 2011. A partir de então, Maria Antônia retorna novamente como liderança, e outra mulher, Márcia Soares, se torna a vice-liderança por algum tempo. Isso nos mostra que, na Terra Indígena Linha Glória, a liderança gira em torno da figura feminina. São as mulheres que estão à frente dos encaminhamentos, demandas e reuniões do grupo. Sobre essa questão, o depoente $\mathrm{H}$ informa:

\section{[...] conhecendo um pouco da história dessas famílias que ali estão, que o fortalecimento de algumas lideranças e assim, a escolha destas para cargos de liderança dentro $e$ fora da aldeia, veio junto com a história da territorialidade do povo Kaingang no Rio Grande do Sul. A Maria Antônia Soares é uma liderança de destaque entre os Kaingang. Ela, assim como a Maria Sandra, vivenciou e aprendeu com a liderança do pai, Manoel Soares. Elas contam que várias vezes foram}

expulsas de espaços, como a Gruta do Índio, em Santa Cruz do Sul, espaços no município de Mariante [Venâncio Aires], sempre ao lado do pai. Foi seguindo ele, que retornaram para o Vale do Taquari, espaço onde o pai e seus antepassados tinham vivido. No momento em que ele faltou, repentinamente, pois morreu atropelado na estrada, essas filhas, com apoio e a partir da organização interna, assumiram seu papel. E desde então, elas vêm assumindo, e você percebe que assumem, assim, com muita garra. [...] Maria Antônia, por exemplo, por um tempo, foi a única mulher no Conselho Estadual dos Povos Indígenas (CEPI). Participava, representando a sua aldeia. Maria Sandra, Maria Conceição fizeram parte do Conselho também. Elas eram as únicas mulheres. Hoje as lideranças Kaingang, que vivem nas aldeias em Porto Alegre (Morro do Osso, Lomba do Pinheiro), na aldeia Por Fi em São Leopoldo, na aldeia em Farroupilha, Fochá, em Lajeado e, na própria aldeia, Linha Glória, em Estrela, têm um respeito muito grande e uma consideração muito grande por essas lideranças femininas (EH, 06/05/2011, p. 4).

A participação política de mulheres é algo bastante singular na história Kaingang, na medida em que a maior parte dos documentos e material historiográfico produzidos refere-se, quase que exclusivamente, a aspectos da organização política como sendo do universo masculino. No entanto, Luís Fernando da Silva Laroque (2005), apoiado em fontes documentais, procura demonstrar que, em relação à atuação da mulher dentro do mundo Kaingang, bem como nas relações com as sociedades não índias, o gênero feminino Kaingang sempre esteve presente.

Com o passar do tempo, o grupo localizado junto à BR 386, no KM 360 da rodovia, passou a ser alvo de olhares preconceituosos da sociedade regional e, principalmente, de alguns órgãos públicos que se referiam aos indígenas como "intrusos" ou "sem-terra". Esta questão pode ser verificada em documento oficial do Poder Legislativo de Estrela. 
$O$ vereador Paulo Scheeren disse ter sido informado que os sem-terra que estão à margem da BR 386, próximo a Bom Retiro do Sul, teriam sido levados para um encontro em Porto Alegre, no final da semana, e que vai descobrir se o Poder Público Municipal foi que os transportou, pois se isso aconteceu, é ilegal (ATA n. ${ }^{\circ}$ 27/2001 - SESSÃO ORDINÁRIA da CÂMARA MUNICIPAL de ESTRELA, (grifo nosso).

Em 2001, com o objetivo de chamar a atenção da sociedade estrelense e das autoridades em geral para a situação em que viviam os indígenas da Terra Indígena Linha Glória e, sobretudo, pensando na questão da exclusão e da discriminação às quais este grupo vinha sendo submetido, é que a esposa do vice-prefeito de Estrela, a senhora Loraci Birck, teve a ideia de organizar uma caminhada no dia 07/09/2001, intitulada "O $1^{\circ}$ Grito dos Excluídos de Estrela". Organizada por ela e pelos próprios indígenas, o movimento não teve a repercussão desejada junto aos órgãos públicos de Estrela, que repudiaram o ato, reafirmando assim uma visão preconceituosa para com esta população indígena.

Renato Horn (PPB) disse que todos têm direito de se pronunciar, buscar seu espaço, mas a esposa do vice-prefeito, Inácio Birck, chutou uma bola e fez gol contra. Trouxe uns bugres da BR 386, fizeram um bafafão [...]. Acentuou que a maioria destes indios foram expulsos de Santa Cruz do Sul, e agora querem terra em Estrela.

Gilberto Fensterseifer (PL) [...] disse: "o que queremos com estes bugres aqui? Daqui a pouco alguns deles serão atropelados na beira da BR, pois deitam lá no chão, e dai como fica?"

Larri Schwingel (PMDB) disse: "os bugres, em hora cívica não precisavam ter feito aquilo, não ficou bem para nós, estrelenses" (FIASCO, Jornal Folha de Estrela, 13/09/2001, p. 5).
Percebe-se que há, dentro de um mesmo espaço geográfico, ou seja, do território de Estrela, ou ainda, numa visão mais global, do Vale do Taquari, o que José de Souza Martins (1997) define como "fronteira étnica". Na concepção deste autor, fronteira não é algo determinado geograficamente, mas, essencialmente, o lugar da alteridade. É o lugar do encontro dos que, por diferentes razões, são diferentes entre si, como os indígenas de um lado e a sociedade estrelense, ou nacional, dita "civilizada", de outro. Assim, Martins (1997) enfatiza que o que há de mais relevante para caracterizar e definir fronteira é, justamente, a situação de conflito social. Mas o conflito faz com que a fronteira seja, essencialmente, a um só tempo, um lugar de descoberta do outro e de desencontro. Em outras palavras, o desencontro das fronteiras é o desencontro das temporalidades históricas daqueles que, por diferentes razões, vivem diversamente no tempo da História e, ao mesmo tempo, são contemporâneos.

Neste sentido, a fronteira só deixa de existir quando o conflito desaparece, quando os tempos se tornam um só tempo, quando a alteridade original, que difere culturas étnicas tão distintas, dá lugar a uma alteridade política e o outro se torna a parte antagônica do nós (MARTINS, 1997). Logo, o "conflito" que há entre as duas sociedades - nacional e indígena - é marcado por uma visão do outro, que é diferente de nós, portanto considerado "inferior ou incapaz", e é justamente esta a justificativa que os brancos utilizaram para exterminar milhares de indígenas durante largo período de tempo na História brasileira. Segundo Martins (1997, p. 163), “[...] o que poderia ter sido um momento fascinante de descoberta do homem, foi um momento trágico de destruição e morte". Vivemos numa sociedade que utiliza um discurso de respeito com relação à diversidade étnica e cultural, mas, na prática, supervaloriza apenas alguns grupos étnicos e culturais.

O reconhecimento deste grupo pelo Conselho Estadual dos Povos Indígenas (CEPI) como sendo da etnia Kaingang, ocorreu no ano de 2002, o que possibilitou que a aldeia pudesse ser incluída em programas especiais para comunidades indígenas (BIRCK, 2002). Esta é uma questão de extrema relevância, uma vez que possui um significado que só pode ser entendido a partir do conceito de identidade étnica. Sobre isso, 
Carlos Rodrigues Brandão (1986) destaca que a identidade é, sobretudo, o reconhecimento social da diferença. Ela se constrói baseada em uma dimensão social e simbólica. É uma mistura de consciência, trocas afetivas e reconhecimento, que perpassa pelo pertencimento a um determinado grupo. Portanto, a própria condição engendra a necessidade de lutar pela sua sobrevivência, e nesta luta é necessário estabelecer uma identidade própria, de cada pessoa, mas que é também uma identidade grupal. A participação do grupo no Conselho Estadual dos Povos Indígenas (CEPI), iniciada em 2002, por meio da liderança de Maria Antônia Soares, foi muito importante, pois, a partir de então, o grupo passou a receber maior apoio da Fundação Nacional do Índio (FUNAI) e da Fundação Nacional da Saúde (FUNASA).

Com o reconhecimento da Terra Indígena Kaingang Linha Glória pela FUNAI, em 2002, o Governo do Estado do Rio Grande do Sul, por meio da Secretaria de Educação, foi responsável pela gestão da construção da escola indígena às margens da $\mathrm{BR}$ 386 (um pouco abaixo/ao sul da área atual da aldeia), e sua posterior autorização de funcionamento. Pelo Decreto n. ${ }^{\circ} 41.700$, de 03 de julho de 2002, o então governador do estado do Rio Grande do Sul criou e denominou o referido estabelecimento de ensino como Escola Indígena Manoel Soares. Mesmo não tendo o credenciamento e autorização de funcionamento e "centro de custos", a escola iniciou suas atividades a partir de sua criação.

A escola já estava em funcionamento desde seu ato de criação, há cerca de dois anos, quando então foi regularizada junto ao Conselho Estadual de Educação do Rio Grande do Sul, pelo Parecer 447/2004, em 7 de julho de 2004, como Escola Estadual Indígena de Ensino Fundamental Manoel Soares - Escola de Ensino Fundamental de 1. ${ }^{\circ}$ ao 5. ${ }^{\circ}$ Ano (Of. AJU/GAB/3. ${ }^{a}$ CRE/N. ${ }^{\circ} 849$, de 25/08/2004). Com as reivindicações realizadas pelo professor Carlos Matte à 3. ${ }^{\mathrm{a}} \mathrm{CRE}$, em 2003, houve mobilizações para a realização de melhorias na escola, resultando na construção de um sanitário feminino, com vaso e uma pia, um sanitário masculino com um vaso, uma pia e um box com chuveiro. À frente da área construída foi adaptada uma pequena cozinha para ser utilizada no preparo da merenda escolar.
Conforme documentação do Ministério Público Federal/Lajeado, a área de terras da aldeia, em 2004, era de aproximadamente oito hectares. Havia dezenove casas construídas próximas ao trevo de acesso a Bom Retiro do Sul, ou seja, no local onde a escola se encontra na atualidade. Muitas dessas casas estavam em condições precárias. Eram feitas de madeira e cobertas de lonas (CERTIDÃO - Ministério Público Federal, 25/05/2004). Diante desta situação, a líder da Terra Indígena, Maria Antônia Soares passou a reivindicar, junto aos órgãos públicos competentes, a construção de novas casas. Em 2005, o CEPI informou que a área de terras seria ampliada para catorze hectares, e, com isso, seriam construídas vinte e uma casas, dois galpões e um quiosque para a venda do artesanato. Para tanto, o CEPI ficaria responsável pela elaboração de um relatório para identificação de toda área, sendo que o senhor Erivelto Villanova (proprietário da área) iria auxiliar na identificação dos limites da área (RELATÓRIO DE REUNIÃO EXTERNA Procuradoria da República da 4. . região, 08/03/2005).

A ampliação da área de terras da aldeia se efetivou, conforme previsto pelo CEPI, em 2005. A construção das casas teve início em março de 2006, após longo período de espera, e foi uma parceria entre o Programa RS Rural Especial (com um investimento de 21 mil reais para compra de telhas e pregos), categoria que contempla os povos indígenas e parte pelo Programa Estadual de Programa Indígena (investimento de 27 mil reais para o custeio da mão de obra), da Secretaria Estadual de Habitação e a CEE (Companhia Estadual de Energia Elétrica), que cedeu a madeira (CAINGANGUES, Jornal Nova Geração, 17/03/2006). As obras foram finalizadas em julho de 2006, beneficiando cerca de cento e trinta pessoas que viviam na aldeia.

Atualmente, a Terra Indígena apresenta um número de aproximadamente trinta famílias, que sobrevivem da venda de artesanato, das doações que recebem do poder público, de pequenas hortas cultivadas por algumas famílias e da prestação de serviços para produtores rurais. Há dois pontos de venda de artesanato situados nas margens da BR 386, bem como uma separação por famílias na utilização desses postos de venda (GONÇALVES, 2008). É importante salientar que este número de famílias é variável, devi- 
A história dos Kaingang da Terra Indígena Linha Glória, Estrela, Rio Grande do Sul/Brasil: Sentidos de sua (re)territorialidade Juciane Beatriz Sehn da Silva, Luís Fernando da Silva Laroque

do à tradicional mobilidade que estes grupos mantêm de se deslocarem pelo grande território, indo e vindo de outros aldeamentos indígenas, como o de Nonoai, por exemplo, de onde provém um grande número de famílias residentes neste local.

Além de Nonoai, algumas famílias que atualmente residem na Terra Indígena Linha Glória também são provenientes da Terra Indígena de Iraí. Os indígenas deslocam-se de um lugar a outro por diversos motivos: para visitar seus parentes, buscar materiais para feitura do artesanato, para buscar alimentos em aldeamentos próximos, participar de reuniões, por motivos de desentendimentos entre eles, para vender seus artesanatos em outras cidades, dentre outros. A mobilidade sempre fez parte da lógica Kaingang ao longo dos tempos.

O Território Kaingang comporta, assim, vários grupos locais onde se distribuem parentes afins. Nesse espaço físico, grupos familiares (extensos ou não) e pessoas se movem constantemente, formando uma ampla rede de sociabilidade cujos individuos compartilham uma experiência histórica e se consideram partícipes da mesma cultura. Unifica-os, portanto, uma consciência mítica, histórica e étnica. Essa rede configura a espacialidade de todo o social que expressa uma unidade sócio-política mais ampla, a sociedade Kaingang (TOMMASINO, 2000, p. 208).

Movimentar-se pelo espaço era algo crucial para a sobrevivência das parcialidades Kaingang e, em virtude deste fato, construíam aldeias fixas, denominadas emã e acampamentos provisórios, os chamados wãre, nas florestas e margens dos rios. Sobre isto, Kimiye Tommasino ilustra o seguinte:

Os dados históricos e geográficos indicam que um território Kaingang tinha, necessariamente, de apresentar um ecossistema variado que lhes permitisse sua reprodução social e cultural. Nas regiões de campo faziam suas aldeias fixas (emã). Faziam também acampamentos ou abrigos provisórios (wãre) nas florestas e margens dos rios, onde permaneciam nas semanas ou meses em que praticavam a caça ou a pesca. Os deslocamentos eram feitos por grupos de parentesco, de modo que sempre havia pessoas no emã e outras no wãre (TOMMASINO, 2000, p. 203-204, grifos do autor).

Dessa forma, assim como no passado, os indígenas da Terra Indígena Linha Glória ainda preservam essa tradição. Os emã (acampamentos fixos), frequentados por eles, são os diferentes aldeamentos existentes na atualidade, então criados pelo SPI e, posteriormente, pela FUNAI, e reconhecidos como TIs (Terras Indigenas) ou Reservas Indígenas. Por sua vez, os wãre seriam aqueles acampamentos provisórios, ou ainda, lugares como, por exemplo, as cidades por onde permanecem às vezes, por semanas, para venderem seus artesanatos como forma de sobrevivência. A mobilidade que ainda continuam a fazer é uma forma também de manter vivas práticas culturais pretéritas e, de acordo com Tommasino (2000, p. 224), "[...] mover-se no espaço significa, assim, mover-se no tempo".

A duplicação da BR 386 na altura do trecho Estrela/Tabaí, aprovada no ano de 2009, e com início das obras no final do ano de 2010, é uma questão bastante latente para a comunidade Kaingang da Linha Glória, no período atual. Esta obra irá afetar diretamente o território da referida comunidade Kaingang e, consequentemente, trará prejuízos de ordem ambiental, econômica e social. Neste contexto, também reascende-se a discussão sobre a legalização das terras da aldeia em Estrela como Terra Indígena, já que a área onde a comunidade está instalada encontra-se em situação irregular, ou seja, depende de regularização fundiária, pois parte das terras é de domínio Federal e outra de propriedade particular do senhor Erivelto Villanova, conforme já fora mencionado anteriormente.

Essa questão vem, desde o princípio, gerando muitas discussões e impasses entre o grupo Kaingang, a Fundação Nacional do Índio (FUNAI) e o Departamento Nacional de Infraestrutura e Transporte (DNIT), visto que, com a duplicação da BR 386, surge à necessidade de desapropriação de parte da comunidade Kaingang, que, embora seja anunciada como sendo "pequena", é importante refletirmos que o espaço atual já é bastante limitado para este grupo,

Soc. \& Nat., Uberlândia, ano 24 n. 3, 435-448, set/dez. 2012 
formado por mais de cento e cinquenta indígenas, que historicamente possuem a tradição de um amplo território, sendo este imprescindível para sua sobrevivência física e cultural.

Diante dos acordos estabelecidos entre a FUNAI e o DNIT com relação à área de terras, em janeiro de 2011, a possibilidade de remanejo dos indígenas da Terra Indígena Linha Glória gerou manifestações do grupo, devido ao fato de não terem sido consultados sobre esta possibilidade de desocupação da área, uma vez que os acordos iniciais não eram estes. Segundo a indígena Maria Antônia Soares da Silva, em documento entregue pelo DNIT em junho de 2010, não estava previsto o remanejo dos indígenas do local (ÍNDIOS, Jornal A Hora, 26/01/2011, p. 7).

Visto que todos os temas que se relacionam a terra no Brasil são conflituosos, especialmente quando se trata da questão indígena de direito a terra, com o grupo indígena Kaingang da Terra Indígena Linha Glória não é diferente, e esta questão se mostra de forma bastante fervorosa com a duplicação. Há um impasse a ser resolvido, que é a legalização e a ampliação daquela área de terras como Terra Indígena. Não há, por parte do grupo, o desejo de deixar o local, como fora preconizado por algumas lideranças políticas municipais, pelo DNIT, e mesmo, pela FUNAI. Há uma relação cosmológica com este território. Os indígenas Kaingang têm plena consciência de que este território fora ocupado pelos seus antepassados e sabem que há comprovação arqueológica dessa ocupação, conforme podemos citar nos estudos de Jairo Henrique Rogge, intitulado "Fenômenos de fronteira: um estudo das situações de contato entre os portadores das tradições cerâmicas pré-históricas do Rio Grande do Sul" (2004) e Luís Fernando Laroque "Guaíba no contexto histórico-arqueológico do Rio Grande do Sul (2002). Da mesma forma, já estão no local há mais de 40 anos. Muitos de seus filhos nasceram ali. Seus umbigos estão enterrados nessas terras. Por tudo isso, há toda uma simbologia e uma relação do grupo com o território.

\section{CONSIDERAÇÕES FINAIS}

Os indígenas Kaingang da Terra Indígena Linha Glória, nesses quarenta anos de ocupação deste território, que é reconhecido por eles como sendo, território dos seus antepassados, empreenderam muitas "lutas" no sentido de serem respeitados como etnia indígena e de reivindicarem seus direitos, sendo sujeitos de sua própria historicidade. Muitas foram as conquistas deste grupo, como por exemplo, o reconhecimento de pertencimento a etnia Kaingang em 2002, pelo CEPI, e a participação efetiva no referido conselho a partir de então; a concessão de uma área de terras maior e posterior construção de casas novas neste local, em 2006; a construção de uma escola indígena para as crianças frequentarem até o $5^{\circ}$ ano; o direito de ter um Agente de Saúde Indígena e um Agente de Saneamento Indígena, dentre outros.

$\mathrm{Na}$ concepção indígena, o território possui uma dimensão sócio-política-cosmológica muito ampla e a relação histórica do grupo com o espaço ocupado se deve ao fato de no passado já terem habitado aquele local, e os antepassados terem ali enterrado os seus umbigos. $\mathrm{O}$ fato de estarem (re) territorializando-se, ou seja, (re) ocupando espaços próximos a áreas urbanas, justamente ocorre porque as cidades que invadiram seus territórios, hoje se mostram como uma nova possibilidade de coleta, porém, conforme afirma Laraia (2004) como nenhuma cultura é estanque, precisaram adaptar-se a esta nova realidade. Hoje, as coletas se dão das mais variadas formas, e a venda do artesanato é uma forma de manter viva a cultura Kaingang.

Verificou-se ao longo de nossos estudos que o grupo indígena Kaingang da Terra Indígena Linha Glória mantém viva diversas práticas culturais na atualidade. A grande maioria dos filhos de seu Manoel Soares nasceu no local, sendo que os partos foram realizados pelas próprias matriarcas; seus umbigos foram enterrados ali, conforme a tradição Kaingang, além do mais continuam a mover-se no espaço de acordo com suas necessidades e com inúmeras permanências da lógica cultural Kaingang.

\section{REFERÊNCIAS}

ATA n. ${ }^{\circ}$ 27/2001. Sessão Ordinária da Câmara Municipal de Estrela, Estrela, 08 out. de 2001.

BARTH, Fredrik. Os grupos étnicos e suas fronteiras. In: LASK, Tomke (org.). O guru, o iniciador e outras 
A história dos Kaingang da Terra Indígena Linha Glória, Estrela, Rio Grande do Sul/Brasil: Sentidos de sua (re)territorialidade Juciane Beatriz Sehn da Silva, Luís Fernando da Silva Laroque

variações antropológicas. Rio de Janeiro: Contra Capa Livraria, [1969], 2000, p. 7-67.

BIRCK, Loraci (org). Comunidade Indigena Kaingang / Estrela/RS. Estrela: 3. ${ }^{a}$ CRE e EMATER, 2002. 7 p. (datiloscrito)

BRAND, Antônio. História oral: perspectivas, questionamentos e sua aplicabilidade em culturas orais. Revista História Unisinos, São Leopoldo, v. 4, n. 2, p. 195-226, 2000.

BRANDÃO, Carlos Rodrigues. Identidade \& Etnia: construção da pessoa e resistência cultural. São Paulo: Brasiliense, 1986. 173 p.

CERTIDÃO de 25/05/2004 - Procuradoria da República no município de Lajeado. Reunião para conhecer as realidades e problemas enfrentados pela comunidade indígena. Ministério Público Federal, Lajeado.

CAINGANGUES vão ter novas moradias na Glória. Jornal Nova Geração, Estrela, 17 mar. 2006. p. 8.

CHAGAS, Miriam. Análise da analista pericial em antropologia sobre a comunidade Kaingang de Estrela. Procuradoria da República da 4. ${ }^{a}$ Região, Porto Alegre: 2005. 34 p. (datiloscrito)

EC - Entrevistado C: depoimento [17 mar. 2011]. Entrevistadores: autores do artigo. Estrela: s.e., 2011. Gravação em máquina digital 6.0 Mega Pixels. $32 \mathrm{~min} 39 \mathrm{~s}$. Entrevista concedida aos pesquisadores.

EE - Entrevistado E: depoimento [22 mar. 2011]. Entrevistadores: autores do artigo. Estrela: s.e. 2011. Gravação em máquina digital 6.0 Mega Pixels. $32 \mathrm{~min} 39 \mathrm{~s}$. Entrevista concedida aos pesquisadores.

EH - Entrevistado $H$ : depoimento [06 mai. 2011]. Entrevistadores: autores do artigo. Estrela: s.e. 2011. Gravação em máquina digital 6.0 Mega Pixels. $32 \mathrm{~min} 39 \mathrm{~s}$. Entrevista concedida aos pesquisadores.

FIASCO na Semana da Pátria, na opinião de vereadores. Jornal Folha de Estrela, Estrela, 13 set. de 2001, p. 5.
FIEGENBAUM, Jones. Os artesãos da Pré-História do Vale do Taquari e sua cultura material. 2006. 84 f. Trabalho de Conclusão de Curso (Graduação em História) - Centro Universitário Univates, Lajeado.

Um assentamento Tupiguarani no Vale do Taquari/RS. 2009. 221 f. Dissertação (Mestrado em História) - UNISINOS, São Leopoldo, 2009.

GONÇALVES, Jaci Rocha. Relatório Final de Antropologia na área de duplicação da BR-386, Triunfo, Tabai, Taquari, Fazenda Vila Nova, Bom Retiro do Sul e Estrela-RS, Aldeia Kaingang TI Estrela._Tubarão: Universidade do Sul de Santa Catarina - UNISUL 2008.

ÍNDIOS ameaçam trancar a duplicação. Jornal $A$ Hora, Lajeado, 26 jan. de 2011, p. 07.

KREUTZ, Marcos Rogério. O Contexto Ambiental e as primeiras ocupações humanas no Vale do Taquari. 2008. 150 f. Dissertação (Mestrado em Ambiente e Desenvolvimento). Programa de Pós Graduação em Ambiente e Desenvolvimento, Centro Universitário Univates, Lajeado. 2008.

LARAIA, Roque de Barros. Cultura: um conceito antropológico. 17ed. Rio de Janeiro: Jorge Zahar, [1986] 2004. $117 \mathrm{p}$.

LAROQUE, Luís Fernando da Silva. De coadjuvantes a protagonistas: seguindo o rastro de algumas lideranças Kaingang no Sul do Brasil. História UNISINOS, São Leopoldo, v. 9, n.1, p. 56-59, jan./abr. 2005.

- Guaíba no contexto histórico-arqueológico do Rio Grande do Sul. Guaíba: Ed. do Autor, 2002. 182 p.

MARCON, Telmo. Dados atuais sobre as reservas no Rio Grande do Sul. In: MARCO, Telmo (coord.). História e Cultura Kaingáng no Sul do Brasil. Passo Fundo: Graf. Ed. Universidade de Passo Fundo, 1994. p. 271-278. 
MARTINS, José de Souza. O tempo da fronteira: retorno à controvérsia sobre o tempo histórico da frente de expansão e da frente pioneira. In: Fronteira: a degradação do outro nos confins do humano. São Paulo, 1997, Cap. 4, p. 145-201.

MUSSI, Vanderléia Paes Leite. História Oral: uma proposta metodológica em parceria com os índios ternas em Campo Grande, Mato Grosso do Sul. Mato Grosso do Sul, 2000. 10 p. (datiloscrito)

OF. AJU/GAB/3. ${ }^{\text {a }} \mathrm{CRE} /$. $^{\circ}$ 849, de 25/08/2004 Ofício da 3. ${ }^{a}$ Coordenadoria Regional da Educação, Estrela - RS. Sobre Autorização de funcionamento da Escola Estadual Indígena de Ensino Fundamental Manoel Soares. Procuradoria da República, Lajeado-RS.

OLIVEIRA, Marilda Dolores. Essa terra já era nossa: um estudo histórico sobre o grupo Kaingang na cidade de Lajeado, Rio Grande do Sul. 2010. 89 f. Trabalho de Conclusão de Curso (Graduação em História) - Centro Universitário Univates, Lajeado.

RELATÓRIO de 08/03/2005 - Relatório de reunião externa. Discussão e planejamento de soluções para os problemas da comunidade. Ministério Público Federal, Lajeado-RS.

ROGGE, Jairo Henrique. Fenômenos de fronteira: um estudo das situações de contato entre os portadores das tradições cerâmicas pré-históricas no Rio Grande do Sul. 2004. 241 f. Tese (Doutorado em História) UNISINOS, São Leopoldo.

ROSA, Rogério Réus Gonçalves da. Lenda e mito do cacique Nonohay. In: GOLIN, Tau; BOEIRA, Nelson (coord.). História Geral do Rio Grande do Sul. Povos Indígenas. Passo Fundo: Méritos, v. 5, 2009. p.137-159.

SIMONIAN, Ligia T. Lopes. Política / Ação anti-indígena de Leonel de Moura Brizola. In: GOLIN, Tau; BOEIRA, Nelson (Coord.). História - Rio Grande do Sul - Povos indígenas. v.5. Passo Fundo: Méritos, v. 5, 2009. p. 469-494.
TOMMASINO, Kimiye. Considerações Etnológicas a partir de dois conceitos Kaingang: Ga e Krî. VI REUNIÓN DE ANTROPOLOGIA DEL MERCOSUR. Montevideo. Anais... 2005, 17p. (datiloscrito).

. Os Sentidos da Territorialização dos Kaingang nas Cidades. Curitiba, 2001, p. 01-15 (datiloscrito).

Território e territorialidade Kaingang: resistência cultural e historicidade de um grupo Jê. In: MOTA, Lúcio Tadeu; NOELLI, Franciso S.; TOMMASINO, Kimiye (Org.). Urí e Wãxí - Estudos Interdisciplinares dos Kaingang. Londrina: UEL, 2000. p. 191- 224.

VEIGA, Juracilda. Aspectos fundamentais da cultura Kaingang. São Paulo: Curt Nimuendajú, 2006. 256 p.

O processo de privatização da posse de terra indigena. Disponível em: <http://www.portalkaingang.org/privatizacao_juracilda.pdf/2006a>. Acesso em: 10 abr. 2011. 